\title{
ETHICS IN PROFESSIONAL INTERACTION Justifying the limits of helping in a supported housing unit
}

Kirsi Juhila and Suvi Raitakari

\section{SUMMARY}

The paper studies the construction of ethics in interactions between professionals in meetings, in relation to the rationing of resources. The research context is a supported housing unit targeted to clients with mental health and substance abuse problems. The service is provided for a municipality, which expects good progress of the clients. The research question is: how do the professionals produce implicit ethical justifications for setting limits to helping, even though the need for professional help is not called into question? Five types of justification appear in the data covering 28 meetings. However, these types of justification do not solve the central ethical difficulty arising in the conversations. Limiting help would easily push people out of reach of all help. Thus, in spite of the talk about ethical justification, the workers do not ultimately resort to limiting help in situations with no real alternatives for getting help. The ethical principle of following non-exclusionary practices is highly prioritised.

Keywords: professional ethics, ethnomethodology, interaction, ethical difficulty, rationing, justification, help, need 


\section{ETHICS IN PROFESSIONAL INTERACTION}

\section{Justifying the limits of helping in a supported housing unit}

\section{INTRODUCTION}

Ethical issues are an inseparable part of professional social work. Ethics is studied during education, textbooks are written about it and codes are established by professional associations. The professionals in the field are expected to know the ethical principles shared by the profession and to apply them in their daily work. In addition it is emphasised that good professional practice relates to the personal values and moral character of professionals (e.g., McBeath and Webb, 2002; Clark, 2006). Parallel to these two interpretations of ethics- ethics as external codes and as characteristics of persons doing the work- there is also the suggestion that ethics should be approached by studying how it is produced in social work practices (e.g., Rossiter et al., 2000; Rossiter, 2005; Banks and Williams, 2005). Applying the norms of professional ethics is not a straightforward or individual process. As Amy Rossiter et al. (2000, p. 95) put it: 'the application of those norms is interpretive, and depends on the local and particular features of each situation'. Because of this it is important to study professional ethics in action, as it occurs in the mundane interactional practices of work (see Banks, 2001, pp. 160-185). Our study follows this line of research.

The research context is a supported housing unit situated in a large Finnish city. The unit is targeted to clients who suffer from mental health and substance abuse problems. The data 
consists of interactions in meetings among the unit's professionals. The focus lies on interactional episodes where the professionals discuss putting limits to their helping work in situations where they nevertheless consider that some kind of professional help is needed. This links the study to analyses of professional practices dealing with the rationing of resources, client selection, criteria of clienthood, the assessment of client eligibility and the categorisation of clients as 'good' and 'bad' (e.g., Lipsky, 1980; Dingwall and Murray, 1983; Light and Hughes, 2001; Loseke, 1992; Griffiths, 2001; White, 2002; Juhila, 2003; Hall et al., 2006). Putting limits to helping is an ethically difficult topic. The analysis aims to show how this difficulty is dealt with in the meeting interactions.

Although the research is based on the mundane practices of one Finnish organisation, the ethical difficulty studied here is widely recognized by social and health work actors. Professionals cannot escape the duty of rationing resources. In their organisations they are inevitably involved in discussions where the type and quantity of the help demanded is deemed to be more than the organisation can possibly supply (e.g., Lipsky, 1980, pp. 81-156; Beckett and Maynard, 2005; pp. 89-105).

\section{SETTING AND DATA}

The supported housing unit offers community-based services for people who have been assessed as having mental health and substance abuse problems. The unit is part of a larger mental health organisation (NGO), which provides services to a municipality. As the purchaser, the municipality expects good quality and above all, effective service. The principal aim of the supported housing unit is to strengthen the clients' ability to lead independent lives, in other words, to rehabilitate them. Thus, no one is expected to stay in the 
unit permanently, but the clients are expected to move on after a maximum rehabilitation period of three years. The unit can be defined as a sort of half-way house: the need for help must not be too slight, but not too great either. The client eligibility criteria are based on these premises.

The unit was set up in 2004 to respond to the needs of citizens who appear not to receive professional help elsewhere. To take an example, the services specialising in either substance abuse problems or mental health problems often define people who are deemed to suffer from both of these as too difficult to help. On the other hand, institutions offering intensive or longterm care, such as psychiatric hospitals and nursing homes, usually assess such people as not needing the all-inclusive help provided by these institutions. As a small-scale service provider the unit obviously cannot meet the needs of all those who have been excluded by these other helping organisations. Consequently, it also has to consider the limiting of help.

The unit is located in a conventional high-rise housing estate, where 10 council flats have been reserved for the unit's clients at any one time. A facility in the same area called the 'support centre' functions as a meeting point for both the clients and professionals. The clients may visit the support centre, and the professionals organise group and work activity there. The five professionals employed have previous experience of both social and mental health work.

The research data consists of 28 meetings among the professionals in the period of April 2004 to June 2006. The permission to record and use the data was given by the Board of the mental health organisation which maintains the unit. The average length of the meetings is 80 minutes, and all the workers are present. The meetings follow a uniform agenda. They start 
with a discussion of general issues related to the unit's activity and the eligibility of potential new clients, followed by the main part of the meeting, during which the workers talk about the situations of the current clients. Case talk about the current clients does not have a pre-set agenda. It is initiated by the client's key worker, but after the opening (s)he assumes no special authority in the course of the discussion. The purpose of this talk is to assess the clients' progress or lack of it, and to reflect on how the workers have succeeded in helping the clients or failed to do so. During the two-year period of research, the clientele was fairly stable in spite of the rehabilitation expectations, as the same nine clients were talked about at each meeting. The clientele of the unit was male-dominated: only about $20 \%$ of the clients were women.

\section{STUDYING ETHICS IN ACTION}

The study is anchored to an ethnomethodological frame of reference (Garfinkel, 1967; Heritage, 1984; de Montigny, 2007) and to research on social and human service work, in which naturally occurring conversations between professionals and clients or among professionals is analysed (e.g., Jokinen et al., 1999; Hall et al., 2003 and 2006; Taylor and White, 2000). Ethnomethodology approaches people's activities as fundamentally interactional. Interaction occurs mainly through language, which we use in describing and explaining things that happen to ourselves and others, in order to make sense of them (Francis and Hester, 2004, pp. 1-19). In this study the application of the ethnomethodological orientation means a detailed analysis of the kinds of limits to helping that the professionals produce in the meeting conversations and the way in which this is done. 
Limiting the help provided by the supported housing unit is an ambiguous theme, which the workers themselves construct as a topic in the course of meeting conversations. When discussing the topic they simultaneously talk about the rationing of resources (Lipsky, 1980). The talk is linked with the discourse of professional ethics, though the workers do not explicitly mention ethics during their conversations. We argue that the professionals who take part in the meeting conversations share the principles of professional ethics discourse, set forth in the ethical codes of professional associations, for instance (Banks, 2001, pp. 84-111). The code of ethics adopted by the Finnish social work union (Talentia Union of Professional Social Workers, 2007) follows the code set by the International Federation of Social Workers (International Federation of Social Workers and International Association of Schools of Social Work, 2004). At a general level these codes share the view that the social work profession aims at enhancing people's wellbeing and fights against discriminatory and exclusionary practices.

The aim to ensure people's well-being and the simultaneous struggle to ration the unit's resources produce ethical problems, which are discussed in talk that deals with the clients' situations. Rationing resources for the purpose of limiting help is ethically difficult, for it can be defined as a discriminatory and exclusionary practice. This applies especially in this unit that was set up to eliminate gaps in the helping system and to counteract such practices. A more specific research question arises out of this ethically difficult set-up: how do the professionals produce implicit ethical justifications for setting limits to helping when the need for professional help is not questioned?

In the meeting data, all conversation episodes where the workers discuss the limits of their helping activity were identified. The total number of these episodes is 36 . The episodes are 
evenly distributed in that the matter is discussed at least once in every meeting. In these episodes, we located five types of implicit ethical justification:

1) The unit deals with certain kinds of problems only

2) Clients need more intensive care and control

3) Excessive care produces dependency

4) Clients make their own choices in life

5) The interests of other clients ought to be considered.

In the following section we will explore each of the five types by an analysis of one episode. The episodes are selected to represent the range of justifications displayed in the data. The meeting talk was transcribed verbatim. The original language of the meetings is Finnish, but the excerpts have been translated into English for the purposes of this paper. All references to names, localities and services that might threaten the anonymity of the persons involved have been changed or removed.

\section{JUSTIFYING THE LIMITS OF HELPING}

1. The unit deals with certain kinds of problems only

This type of justification, which occurs a total of 10 times in the data, is often produced by the workers in the meetings when talking about potential new clients to be selected for the unit. If the candidate is selected, the situation is ethically simple in the sense that the unit decides to respond to the need for help. In contrast, discussions on a potential refusal to help are always associated with a justification of this act, which shows that the matter is ethically difficult. Gale Miller and James A. Holstein (1991) write about social problems dealt with by streetlevel bureaucracies, where an essential element is constructing the mutual division of labour 
between various helping organisations. The different organisations are defined as dealing with different problems. Non-selection and therefore non-response to the need for help can thus be justified by interpreting the candidate as not belonging to the category of those helped by a given unit, and thus not eligible for support, (see Loseke, 1992). Because the supported housing unit studied here is a fairly new actor in the field of helping work, its position and task are not yet established or generally known. Thus, in their meetings the workers repeatedly discuss how the professionals in other helping organisations often refer clients who in the workers' interpretation should not properly be dealt with by the unit.

The background of the following discussion is that the local psychiatric hospital actively searches for places for patients assessed as not needing hospital treatment. The unit is one potential option and thus under pressure to provide such places.

\section{Extract 1}

P1: There was a strong message from the psychiatric hospital wards, that if at this stage the unit [refers to the supported housing unit] is full, there must be another option for them then. There's just this big question mark and they must have some other option for sending people for further treatment.

P2: Well we'll just have to think about it in good time next year about whether this [refers to the unit] is going to be it. Or are we going to develop this work so that it might be done someplace else in addition to this housing estate. And are we happy with the municipal housing foundation telling us that ten flats is the maximum? Would it be possible to have any more flats? I mean this is a pilot really, so it's one of those trial projects.

P1: Exactly. 
P2: And another thing I've really thought quite a lot about just as you said, is getting 14 inquiries from possible clients. We have to think very carefully about it. I mean, is it going to be possible at all? What service helps those who can't be accepted by a service like ours?

P1: Yes, that is so.

P3: Would it mean a higher degree of support, for we often have the problem that people can't really cope here?

In this episode the talk is particularly about the 'division of problems' between the psychiatric hospital and the unit. Professional 1 opens the topic by producing the challenge to helping: there are people on the hospital wards who need somewhere to go, but the unit has no space. The situation is defined as ethically difficult, for it appears that a suitable place cannot be found for some people who need help. If nothing exists, this would lead to the exclusion of, and even discrimination against, a certain group of people. As the talk continues the workers begin to discuss who is responsible in this ethically problematic situation. Is it the hospital, which cannot sort out further treatment, or is the unit also responsible? At first, in the turn by Professional 1, it seems like the buck is passed to the hospital: 'they must have some other option'. After that, however, Professional 2 allocates some of the responsibility to the unit as well. Perhaps the unit should not be content with the number of flats currently offered by the local authority, since more help is clearly needed. This opinion is also supported by another worker.

At the end of the conversation, Professional 2 further continues the discussion of this ethical problem by creating a third option for helping. The third option would be situated between the hospital and the unit, i.e., it would be targeted to people who on the one hand no longer need 
to be in the hospital, but on the other hand need a place with more support than can be offered by the unit. However, the workers do not give a specific name for such a helping unit, for it may not even exist at that point. In this conversation the workers give implicit ethical justifications for the setting of limits to their helping by invoking the unit's task. Within the scope of its resources (number of flats), the unit cannot respond to all requests for help, but in addition, the candidates' need for help must be appropriate, not too great. However, the ethical problem cannot be solved completely, as apparently no suitable options exist for those who need more help. This unsolved problem is strongly present in the conversation, as the workers discuss questions of responsibility, the stretching of the limits of their own unit and the possibility of creating new options of helping.

2. Clients need more intensive care and control

This type of justification, which was found a total of seven times in the course of meeting conversations, also invokes the organisation's tasks in the field of helping work, as was the case with potential client relationships. The workers construct certain clients as clearly needing more intensive care and control than is possible in the unit. So, if they start out from the clients' needs, they must direct these clients to some other helping organisation. The following example shows the elements of this type of justification in a very concise form. The professionals discuss the situation of a client who appears not to progress as the workers hope:

\section{Extract 2}

P2: I'm wondering what really is the right place in this world for someone like Jali?

P1: We've been thinking about that. 
P3: Yes that's what we do think about.

P4: Every time we visit him at home we notice it.

P1: More support. This just isn't enough for him because you can see he's afraid and anxious all the time.

P3: He was really anxious yesterday when he left here.

P1: Yes.

P3: So that's like what he's telling you all the time.

P2: So in this case it's cooperation with other services that provide treatment.

P5: Yes.

P3: And there's going to be a meeting about that.

P5: And hey something you'll have to remember is that the team is strong, and is able to direct someone to somewhere else outside the unit.

P1: A better place could be found for him so he wouldn't panic as badly.

P5: He can't just be thrown out.

In this episode Professional 2 begins to talk about Jali in a way that clearly defines his situation as a cause for concern. Opening the conversation with a question about the right place for someone like Jali suggests that the unit is not the right place for people of his kind. Three other workers confirm the relevance of this doubt by responding to the opening question in a succession of complementary turns. They have also been wondering about the same thing. Professional 4 further confirms the actuality and repeated nature of the matter: 'every time we visit him at home we notice it'. In this way, the workers jointly produce the problematic nature of the matter from the viewpoint of helping. Jali clearly needs something ('the right place'), but what is it he needs? 
The conversation continues with a discussion of Jali's needs, as Professional 1 begins to define the content of help that would be appropriate for Jali: he needs 'more support'. The comparative form and the formulation 'this just isn't enough for him' confirm the emerging interpretation that the unit is not capable of helping this client. The client's continuous fear and anxiety are constructed as the cause of this incapability. The situation is defined as acute, having last been noted the day before. The workers not only read the need for more intensive help from the client's behaviour, but also interpret that he himself is sending out a message to this end. During the conversation an interpretation based on the client's needs and thus ethically justified emerges: the client could be better helped somewhere else. This interpretation justifies setting limits to the help offered by the unit. At the end, the workers define the limiting of help in situations of this kind as high-quality professional activity: the unit and its workers recognise their own knowledge, skills and therefore also the limits of their helping (see Clark, 2000, p. 53; Beckett and Maynard, 2005, p. 81). Ultimately, however, this activity is ethically justified only if a more appropriate place is found for the client, and so far at least they do not know of anything of this kind. The final turn in the conversation on Jali is important from an ethical point of view. Even if the unit might not be the proper place for this client, it would not be right to discharge him unless another place was found. Clients cannot be just turned out with nowhere to go.

\section{Excessive care produces dependency}

While the previous type of justification was concerned with the definition of the clients' needs as too great, the third type continues on the same theme, but with arguments coming from a different direction. The workers self-critically consider that they may have cared excessively for some clients. They justify this assessment by saying that excessive care may turn against 
the clients and produce dependency. The clients might not really need so much support, but through its own activity the unit has created the need for care and keeps it up through its practices. For this reason, in the clients' own interest, limits must be set to the helping. There were four instances of this type of ethical justification in the data.

In the next extract the workers talk about a client whose ability to take care of even his basic needs has caused concern for some time already.

\section{Extract 3}

P1: My personal opinion is that, if we notice these situations that Tarmo's run out of money and he has no food, then we shouldn't start bringing food to him but instead he'd have to go to an institution. Because in my view that's where the limit goes, that we can't start feeding anyone.

P2: Or alternatively if he begins to drink.

P1: Yes, begins to drink and then has no money and there's nothing in the fridge, I think he should then see the doctor and then maybe the mental hospital.

P2: We should make a clear decision about this.

P1: There has to be a limit. We shouldn't really prop him up like.

P2: Yes.

P1: If he can't look after himself.

P2: Because then we'd make it possible.

P1: Yes we'd make all of it possible if it came to that.

P2: We have done that a couple of times.

P1: Yes indeed, we've fetched food for him twice now.

P2: Yes 
P1: I think it's not rehabilitation, if we go and look after his basic needs, like that. He takes a shower and we feed him.

The episode is similar in many ways to Extract 2, which discusses the 'right place' for a person like Jali. Professional 1 mentions 'an institution', which he later specifies as 'maybe the mental hospital', as the right place for Tarmo. However, the types of justifying the limiting of help are different. While Jali's case is discussed from the viewpoint of the insufficient helping potential of the unit, in Tarmo's case the focus falls on assessing the client work at the unit in the sense of what the workers are enabling through their own actions. The workers are defined as active agents whose actions have consequences for the clients' lives. In the first turn Professional 1 proposes the setting of clear limits to helping Tarmo: 'carrying food' to Tarmo or 'feeding' him should not be part of the helping role of the unit's workers. The proposal includes an interpretation of what has caused the lack of food, in other words, running out of money. Professional 2 takes up the proposal and constructs another cause of the situation, that is, starting drinking, and Professional 1 immediately agrees with this and repeats her proposal of limiting the help and concretises the following move, contacting the doctor and considering the mental hospital as an alternative.

Although the worker who opens the conversation stresses that this is his personal view, the setting of limits for helping is eventually produced as a joint interpretation of the two workers. The interpretation includes a self-critical assessment of what the workers enable through their actions and how this relates to the unit's objectives. This is crystallised in the final turn by Professional 1: the unit's objective is to rehabilitate the clients, which will be endangered if the workers begin to look after the clients' basic needs. Instead of rehabilitation, the unit's practices would then enable dependence. The clients will not have to assume responsibility 
for their lives, such as their own finances and their drinking, if the workers help them too much and do not set a clear limit to their helping actions. The workers blame themselves for having helped Tarmo too far, and thus having enabled a life that conflicts with the rehabilitation objectives. They have assumed a paternalistic, dependency-producing orientation towards the client which is commonly seen as ethically objectionable in professional work (see Clark 2000, p. 176). In spite of these justifying arguments to limit help, the ethical problem remains unsolved, and is similar to the one in the previous extract. What will happen to people who are defined as not capable of looking after themselves even after clear limits have been set? What is the proper place for them?

4. Clients make their own choices in life

This type of justification, which comes up 12 times in the meeting data, is based on the argument that clients can only be helped to the extent that they are prepared to accept help. The argument is employed in conversations especially when the professionals produce an interpretation that clients have been given many opportunities to change their problematic behaviour, and means of change have been suggested. As an example, the workers discuss how a client who has been drinking heavily has been given the opportunity to go to detoxification, and the workers have tried to motivate him to accept this treatment. Nevertheless, if the client himself finally decides to refuse this help, he and his will cannot be steamrollered by the workers. So, even if the workers define the client as needing help, they set a limit to their help on the basis that no one can be forced to accept help. Ultimately, the clients make their choices in life themselves. 
The starting point of the following conversational episode is the professionals' increasing concern for a client's drinking habits:

\section{Extract 4}

P1: Eeli is drinking. There was a call yesterday from a client, saying that Eeli is drinking now. That was the only reason he called.

P2: Eeli is one that you really have to wonder about.

P3: Like what is Eeli's proper place, that's right.

P2: He's just not about to change his way of life.

P3: Not even if he had daytime activities.

P2: He's really keen to start all sorts of things now and then.

P3: Yes, like yesterday he had a long working day [in a rehabilitative work place].

P2: And then it goes overboard.

P3: Well he thinks that after all those working hours a man is entitled to have a drink.

P2: So that's what he thinks then.

Again the workers bring up the topic of the most appropriate place for a client. The question is put by Professional 3 as if in direct continuation to the sentence begun by Professional 2: 'Eeli is one that you really have to wonder about'. The joint production of this concern constructs the matter under discussion as a problem acknowledged by all the workers. The problem involves not only Eeli, but also more generally all the clients: Eeli is just one of the persons causing concern because of this. The question about the proper place is produced as a response to the opening by Professional 1, in which he informs the meeting of a phone call he has received from another client, reporting on Eeli's drinking. The opening and the responses to it create not only this generally acknowledged problem, but also the interpretation that 
Eeli's drinking comes as no news to anyone present. As Professional 2 puts it, it is a way of life with Eeli. The client's own agency in his drink-focused way of life is defined as an essential aspect. It is as if the client has chosen his current way of life instead of seeking to change it.

The conversation continues with a discussion of the limits of the unit's helping potential. A client's way of life will not change even if there was a lot of organised daytime activity. In fact, the workers argue that the daytime activity is dysfunctional, for it would seem that 'a long working day' justifies drinking in the client's eyes. The client's agency and his own choice are constructed by the workers in the conversation by a reference to Eeli's own 'thinking'. Appealing to the client's own choice is ethically consistent in the sense that clients' self-determination is a highly emphasised value in professional ethics (see Banks, 2001, pp. 95-96; Beckett and Maynard, 2005, pp. 129-146). During this conversational episode the workers construct the shared opinion that the unit no longer has a great deal of tools to cut down Eeli's problem drinking, for he is committed to a way of life where drinking is a matter of course. While the workers accept this 'difference' or give in to it, they still cannot solve the ethically significant issue of the proper place for Eeli in the event that he must be excluded from the unit.

5. The interests of other clients ought to be considered

A type of justification for setting limits to helping which is less frequent (3 conversation episodes) than referring to clients' personal choices, though closely associated with it, is making reference to the interests of the unit's other clients. This involves the construction of a situation with a choice, in which the unit's clients are set against each other. If one of the 
clients causes direct or indirect trouble to the others, the workers must side with the ones who suffer in the situation. The sufferers are then placed in the position of victims, and those causing the suffering are placed in the position of guilty ones. The guilty position arises particularly when a client's disturbing activity is interpreted as being his or her personal choice. In such a set-up, safeguarding the position and rights of those wronged is defined as an ethically justified action, even if it might lead to limiting the help given to the clients who cause trouble.

The discussion in the following extract deals with a client who has repeatedly failed to follow the unit's shared rules and agreements:

\section{Extract 5}

P1: If you allow him to go on living as he wants, what will happen if he doesn't really try to keep to agreed hours and such? Of course there are certain pressures in a community such as this, what you could call as collective pressure.

P2: The pressure, (why doesn't he comply?), will come from the community

P1: Yes.

P3: Yes, there is a conflict there.

P2: A conflict.

P1: Indeed.

P3: If we require certain things of the other clients as well.

P2: Yes.

The episode starts with the final turn of the preceding conversational episode by Professional 1: the talk concerned a client's way of life which is defined as problematic for the unit. At the 
same time, the turn opens a discussion on the limits of help. The opening turn is presented as a hypothetical question. In this way the worker invites the others to discuss the possibility that the client continues his current way of life in defiance to the rules agreed in the unit. She also provides a direction for the discussion: the matter could best be approached from the viewpoint of 'certain pressures' in the community. By the community she refers to the group formed by the unit's clients. Professional 1 further clarifies her message: 'such as this, what you could call as collective pressure'. The other workers take this up immediately in a way that shows that the workers recognise the situation and are in agreement as to what should be done. It is likely that similar situations have been discussed before. Professional 2 first repeats the words of Professional 1, but then continues to process the theme by placing the clients in two conflicting camps: 'the pressure, (why doesn't he comply?), will come from the community'. The worker more or less takes the position of advocate for the other clients. The other clients expect that in the name of fairness, compliance with the agreed ways of behaviour applies to all clients.

At the end of the episode, the professionals jointly define the situation as conflicting. The expectations should be the same for all clients. Implicitly, the conversation produces the interpretation that if a client is allowed not to comply with the unit rules, the commitment of the others may also be eroded. Thus, one single client may cause considerable trouble in the unit. Therefore general and common interest would ethically justify the removal of the disturbing client from the unit if his behaviour does not change. Just as in the previous examples, the episode ends with nothing definite being said about where a client of this type could be directed. The ethical problem remains unsolved. 


\section{DISCUSSION}

Ethical issues and difficulties are constantly discussed and negotiated in mundane professional work practices, even though the word ethics is not necessarily mentioned at all. In this study we have analysed how professionals jointly produce implicit ethical justifications for potentially setting limits to helping in the supported housing unit. We located five different types of justification.

In meeting conversations, different principles familiar from the ethical codes of social work (International Federation of Social Workers and International Association of Schools of Social Work, 2004; Talentia Union of Professional Social Workers, 2007) struggle against each other. The ethical responsibility to offer professional help when needed and thus avoid exclusionary and discriminatory practices is mitigated by using other ethical principles in order to defend the potential limiting of help. In the first type of justification (the unit deals with certain kinds of problems only), the principle activated can be formulated as follows: the services provided should be based on the skills and competences of the professionals. The professionals' expertise would be wasted and it would be frustrating or even detrimental to the clients if the clients selected needed something that the unit could not supply. The second type of justification (clients need more intensive care and control) also attaches attention to the unit's and the professionals' expertise and to the principle of responding to the clients' real needs. The third type of justification (excessive care produces dependency) arises from the principle that the professionals should promote clients' participation and empowerment. The fourth type (clients make their own choices in life) is linked with the principle of respecting client self-determination. The last type of justification (the interests of other clients 
ought to be considered) can be associated with the principle that professionals should ensure that the clients' choices do not threaten the rights and interests of others.

Thus, the professionals justify the limiting of help with ethical arguments. However, this does not solve the central ethical difficulty arising in these conversations (Banks and Williams, 2005): the termination of the client relationship easily pushes people out of reach of all help. The professionals discuss this problem in the meetings. This is visible in questions as to what the proper places for these people would be, where the clients would be helped if not in the unit, or where the prospective clients will end up if they are not accepted by the unit. By recognising the problem the professionals show responsibility and concern for people who need help. Someone must look after these people and their rights. The supported housing unit was created a few years ago to respond to the needs of a group of people for whom the existing provision of professional help was not sufficient. Consequently, the very reason of the unit's existence obliges the professionals to make sure that they do not uphold an exclusionary and discriminatory policy.

In all the conversation episodes the ethical problem remains unresolved, while both the act of limiting help and the duty to respond to the need for help are justified. The meeting interaction constructs a social reality which has the effect of causing consequences. The consequences can be of two kinds: either help is limited, or the needs are responded to regardless of problems. As was mentioned in the beginning of the article, the same nine clients were discussed in each meeting during the two-year period covered by the data. This means that none of the clients were excluded from the unit during that period - even when helping a particular client was repeatedly defined as ethically questionable, using the types of justification of the limits of helping analysed in this paper. As researchers we have had the 
opportunity of following up life in the unit even after the period covered in the data. On the basis of what we have observed, the option of limiting help has mainly been resorted to in the case of prospective clients, and the professionals continue with their rehabilitation work among the existing clients despite its difficulties. This being so, our concluding argument is that although the workers reflect continuously on the ethical justifications of the limits of helping, this does not mean that they end up limiting help in situations where no real alternatives for getting help for their present clients exist. This shows that the ethical principle of following anti-discriminatory and non-exclusionary practices is highly prioritised.

However, the workers have to struggle with the fact that the municipality as service purchaser expects good rehabilitation results and an adequate progress of clients so that new clients can be taken in (Banks, 2004, pp. 151-155). This creates pressure towards excluding clients who are constructed in the ways seen in the episodes: needing more intensive care, being too dependent on help, preferring self-destroying choices in life, and disregarding shared rules. It may be claimed that excluding these clients is a reasonable rationing of resources. The entire existence of the unit may be threatened if the purchaser is not convinced of the results of the activity; no one is meant to stay at the unit permanently. The impact of the expectation of good results is also strongly present in the meeting talk. Saario and Raitakari (2009), who have studied the same data corpus, call this talk effectiveness argumentation: they refer to the workers' discussions of better ways of demonstrating the economical and progressive aspects of their work (see also Juhila et al forth).

Our hypothesis is that the more strictly the unit is steered on the basis of measurable results, the narrower the workers' opportunities for non-exclusionary practices will become. The greatest concern should be felt over what happens to people who, despite their need for help, 
will be rejected even by this unit and other similar helping organisations set up to catch those not caught by other services. Using ethical justification, these people can be interpreted as needing a different kind of help, but the kind of helping places needed, which provide longterm care, for example, are not necessarily available at all.

\section{Acknowledgements:}

The article is part of the research projects 'Dilemma between Control and Support in Social Work Practices' and 'The Categorization of the Most Difficult Cases in Social Work Practices' funded by the Academy of Finland and conducted in the Department of Social Policy and Social Work at the University of Tampere. We would like to acknowledge the important contribution of the other members of the projects to this text, as well as comments from colleagues in the international research group DANASWAC.

\section{REFERENCES}

Banks, S. (2001) Ethics and Values in Social Work, 2nd edn, Palgrave, Basingstoke.

Banks, S. (2004) Ethics, Accountability and the Social Professions, Palgrave Macmillan, Basingstoke.

Banks, S., Williams, R. (2005) 'Accounting for Ethical Difficulties in Social Welfare Work: Issues, Problems and Dilemmas', British Journal of Social Work, Vol. 35, no 7 pp. $1005-1022$.

Beckett, C., Maynard, A. (2005) Values and Ethics in Social Work: An Introduction, Sage Publications, London.

Clark, C. L. (2000) Social Work Ethics: Politics, Principles and Practice, Palgrave, Basingstoke.

Clark, C. (2006) 'Moral Character in Social Work', British Journal of Social Work, Vol. 36, no 1 pp. $75-89$.

de Montigny, G. (2007) 'Ethnomethodology for Social Work', Qualitative Social Work, Vol. 6 , no 1 pp. $95-120$

Dingwall, R., Murray, T. (1983) 'Categorization in Accident Departments: 'Good' Patients, 'Bad' Patients and 'Children', Sociology of Health and Illness, Vol. 5, no 2 pp. 127148.

Griffiths, L. (2001) 'Categorising to Exclude: the Discursive Construction of Cases in Community Mental Health Teams', Sociology of Health and Illness, Vol. 23, no 5 pp. $678-700$.

Harris, J. (2003) The Social Work Business, Routledge, London.

Ethics in Social Work: Statement of Principles, [Online], Available: http://www.ifsw.org/en/p38000324.html, [8 Oct 2008].

Francis, D., Hester, S. (2004) An Invitation to Ethnomethodology: Language, Society and Interaction, Sage Publications, London. 
Garfinkel, H. (1967) Studies in Ethnomethodology, Polity Press, Cambridge.

Hall, C., Juhila, K., Parton, N., Pösö, T. (eds.) (2003) Constructing Clienthood in Social Work and Human Services: Interaction, Identities and Practices, Jessica Kingsley Publishers, London.

Hall, C. Slembrouck, S., Sarangi, S. (2006) Language Practices in Social Work: Categorisation and Accountability in Child Welfare. Routledge, Oxon.

Heritage, J. (1984) Garfinkel and Ethnomethodology, Polity Press, Cambridge.

International Federation of Social Workers and International Association of Schools of Social Work (2004) Ethics in Social Work: Statement of Principles, [Online], Available: http://www.ifsw.org/en/p38000324.html [10 Nov 2009].

Jokinen, A., Juhila, K., Pösö, T. (eds.) (1995) Constructing Social Work Practices. Ashgate, Aldershot.

Juhila, K. (2003) 'Creating a 'Bad' Client: Disalignment of Institutional Identities in Social Work Interaction', in Constructing Clienthood in Social Work and Human Services: Interaction, Identities and Practices, eds. C. Hall, K. Juhila, N. Parton, T. Pösö, Jessica Kingsley Publishers, London, pp. 83-95.

Juhila, K. Hall C., Raitakari, S. (forthcoming 2010) Accounting fot the Clients' Troublesome Behaviour in a Supported Housing Unit: Blames, Excuses and Respinsibility in Professionals' Talk. Journal of Social Work, Vol 10, no 1.

Light, D. W., Hughes, D (2001) 'Introduction: A Sociological Perspective on Rationing: Power, Rhetoric and Situated Practices', Sociology of Health and Illness, Vol. 23, no 5 pp. 551-569.

Loseke, D. R. (1992) The Battered Women and Shelters: The Social Construction of Wife Abuse, State University of New York Press, Albany.

Lipsky, M. (1980) Street-level Bureaucracy: Dilemmas of the Individual in Public Services, Russell Sage Foundation, New York.

McBeath, G., Webb, S. A. (2002) 'Virtue Ethics and Social Work. Being Lucky, Realistic and not Doing Ones [Sic]duty', British Journal of Social Work, Vol. 32, no 8 pp. 10151036.

Miller, G., Holstein J. A. (1991) 'Social Problems Work in Street-Level Bureaucracies: Rhetoric and Organizational Process', in Studies in Organizational Sociology, ed. G. Miller, Jai Press Inc, Greenwich, pp. 177-199.

Parrott, L. (2006) Values and Ethics in Social Work Practice. LearningMatters, Exeter.

Rossiter, A. (2005) 'Discourse Analysis in Critical Social Work: >From Apology to Question', Critical Social Work, Vol. 6, no 1, [Online], Available: http://www.criticalsocialwork.com/ [8 Oct 2008].

Rossiter, A., Prilletensky, I., Walsh-Bowers, R. (2000) 'A Postmodern Perspective on Professional Ethics', in Practice + Research in Social Work: Postmodern Feminist Perspectives, eds. B. Fawcett, B. Featherstone, J. Fook, A. Rossiter . Routledge. London, pp. 83-103.

Saario, S., Raitakari, S.(2009) 'Purchaser-Provider Model and Mental Health Rehabilitation: A Study of Practitioners' Effectiveness Argumentation in a Finnish Supported Housing Unit, unpublished manuscript (submitted to International Journal of Social Welfare).

Talentia Union of Professional Social Workers, The Committee on Professional Ethics (2007) Work, Values, Life, Ethics: Ethical Guidelines for Social Welfare Professionals, [Online], Available: http://www.talentia.fi/files/4599_EthicalguidelinesbyTalentia.pdf [10 Nov 2009].

Taylor, C., White, S. (2000) Practising Reflexivity in Health and Welfare: Making Knowledge, Open University Press, Buckingham. 
White, S. (2002) 'Accomplishing 'the Case' in Paediatrics and Child Health: Medicine and Morality in Inter-professional Talk', Sociology of Health and Illness, Vol. 24, no 4 pp. 409-435. 